\title{
Reassessment of the conservation status and protected area coverage of Taiwanese birds: How distribution modelling can help species conservation
}

\author{
TSAI-YU WU, BRUNO A. WALTHER, YI-HSIU CHEN, RUEY-SHING LIN \\ AND PEI-FEN LEE
}

\section{Summary}

Taiwan has 145 breeding bird species, but so far no comprehensive attempt has been made to model their distributions. For the first time, we bring together various datasets to model the distributions of the 116 bird species with sufficient sampling coverage. We improved on previous limited modelling efforts by using ensemble modelling, based on five well-performing modelling approaches: multiple discriminant analysis, logistic regression, genetic algorithm for rule-set production, ecological niche factor analysis and maximum-entropy. We then used these ensemble models to improve our knowledge of the status of each bird species by (I) calculating each species's coverage of Taiwan, (2) calculating each species's coverage by Taiwan's protected area network, and (3) comparing these two conservation-relevant measures with already established measures to highlight those species whose status may need to be reassessed. We categorised each species's coverage of the entire study area as measured by their modelled distributions into four quartiles, thus establishing a new measure of rarity called 'range quartile' which we used to highlight the 22 species with a limited distribution on mainland Taiwan. We also calculated that overall, $29.8 \%$ of the distribution ranges of the 116 modelled species are covered by Taiwanese protected areas. We then identified those species whose status may need to be reassessed because of possible conflicts between the respective conservation-relevant measures. Thus we identified 1o species which are first-quartile species $<5 \%$ of whose distributions are protected, of which only five are considered threatened. We also identified another 12 species with limited distributions, 30 species with limited protection and 19 species whose status may need to be reassessed for various reasons. We recommend that range quartile and protected area coverage be incorporated into future assessments of the conservation status and protected area coverage of Taiwanese birds.

\section{Introduction}

Taiwan is an important hotspot of endemism for many taxa, including birds. While Taiwan has a relatively well established protected area network which covers almost $20 \%$ of its area, it also faces multiple challenges to its biodiversity due to unsustainable economic growth and its environmental consequences. Therefore, studies of the conservation status of Taiwan's avifauna are urgently needed.

More than 570 bird species have been recorded in all of Taiwan (Chinese Wild Bird Federation 2010), and 145 species breed on mainland Taiwan (Fang 2008) of which 17 species (12\%) are endemic (Chinese Wild Bird Federation 2010). The first comprehensive avifauna of Taiwan was 
recently published (Severinghaus et al. 2010) and, correspondingly, location databases on Taiwanese birds have grown to such an extent that data coverage for most species is now sufficient to use statistical approaches to model their distributions.

Efforts to use this newly available information for macroecological and conservation-related studies have so far been incomplete. Previous studies focused only on species richness patterns without the use of distribution modelling: in a local region (Hsu et al. 2004, Ko 2004, Peng 2008), Taiwan's mountains (Shiu and Lee 2003) or all of Taiwan (Lee et al. 2004). Early modelling techniques were then used to study bird distributions in a local region (Koh et al. 2006a, Koh et al. 2006b) or of a single species or subfamily (Ko et al. 2009a). A hotspot analysis using Taiwan's birds was restricted to 14 out of the 17 endemic bird species (Ko et al. 2009b).

Here for the first time we model the distributions of all Taiwanese breeding bird species with sufficient sampling coverage. We improved on previous modelling efforts by choosing the best models from several model runs with the help of AUC scores and then combining these chosen models into an ensemble model (Araújo and New 2007, Barbet-Massin et al. 2009, Thuiller et al. 2009). We then used these ensemble models to improve our knowledge of the status of each bird species by (I) calculating each species's coverage of the entire study area, mainland Taiwan, (2) calculating the proportion of each species's range covered by Taiwan's protected area network, and (3) comparing these two conservation-relevant measures with already established measures to highlight those species whose status may need to be reassessed in light of this new information.

\section{Methods}

\section{Study area}

Our study area is the island of Taiwan which covers latitudes $22^{\circ}-25^{\circ} 18^{\prime} \mathrm{N}$ and longitudes $120^{\circ} 27^{\prime} \mathrm{E}-122^{\circ} \mathrm{E}$ with a maximum elevation of $3,952 \mathrm{~m}$ (Figure 1a). It can be roughly divided into an almost flat western plain, which has been highly modified by humans, and the mountainous areas in central and eastern Taiwan which comprise almost $65 \%$ of the island and are much less developed, and in some parts almost inaccessible to humans. The climate ranges from tropical in the south to subtropical in the north and alpine in the high mountains, with a mean annual temperature of $18.0^{\circ} \mathrm{C}$ and an average annual precipitation of $2,510 \mathrm{~mm}$. The natural vegetation is almost exclusively forest, except at high elevations and river floodplains. Except for some almost inaccessible mountain areas, all parts have been heavily modified by human influence. We divided our study area into a total of 36,022 grid cells of 1 x I km.

\section{Determining species status}

For this study, we selected the 145 bird species (Appendix $\mathrm{S}_{1}$ ) that are listed as breeding species on the main island of Taiwan (Fang 2008). To determine the status of each species regarding its endemicity, rarity, global and Taiwanese status, we consulted a variety of sources (see Appendix Si). In general, the status of Taiwan's fauna is based on the Wildlife Conservation Act of Taiwan (http://www.forest.gov.tw/ct.asp?xItem $=21726 \& \mathrm{ctNode}=249 \& \mathrm{mp}=1$ ). This states that all wildlife shall be classified into two categories: A) protected species, which are either (I) endangered species, (2) rare and valuable species, or (3) other conservation-dependent wildlife; and B) all other species not covered by these three definitions. To distinguish between categories A and B, the Directions for Evaluating Wildlife Categories (http://www.afasi.gov.tw/ct.asp?xItem $=28569$ \&ct Node $=1917 \& \mathrm{mp}=1$ ) state that the following criteria should be evaluated for each avian species: 1) distribution, 2) abundance of adult individuals, 3) population trends, 4) taxonomic status, and 5) the combined threat from hunting pressure, capture for trade and the rate of habitat loss. The Wildlife Conservation Advisory Committee is then charged with determining which species falls into category A, while the National Principal Authority is responsible for the compilation of the 
(a)

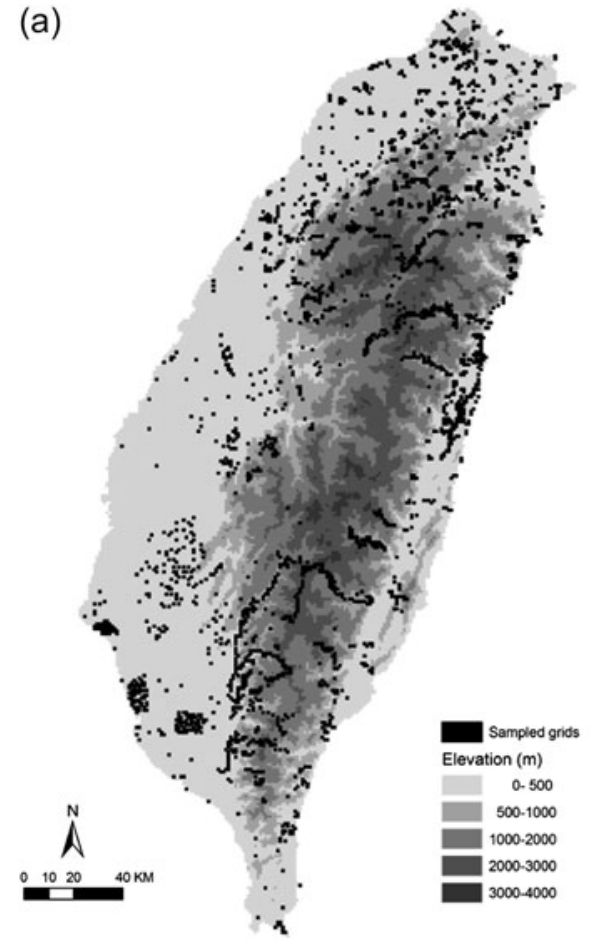

(b)

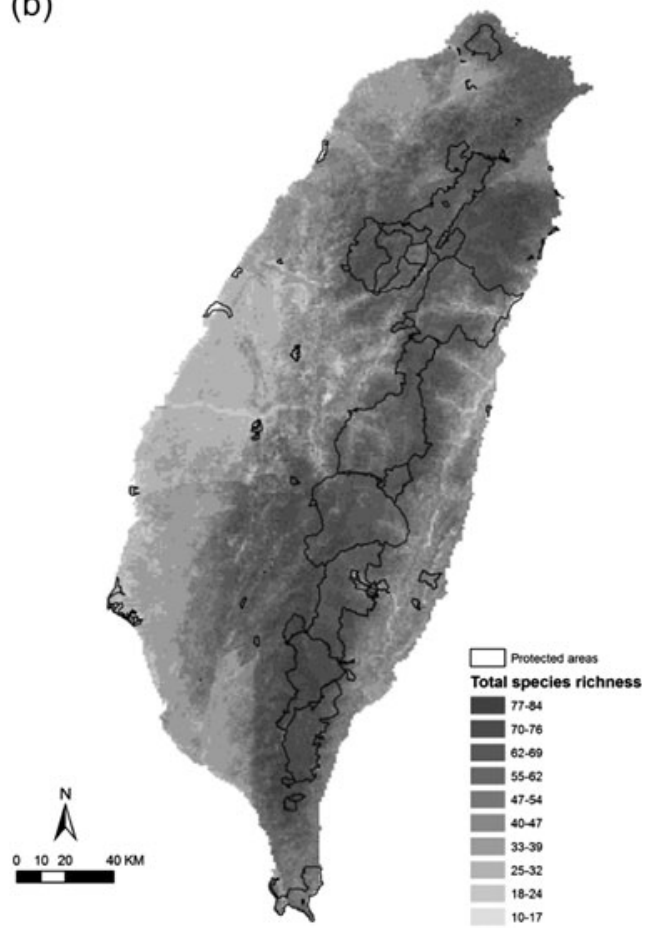

Figure 1. (a) Topography of Taiwan showing elevational ranges and the locations of the 2,455 sampled I x I km grid cells used in this study. The total number of grid cells is 36,022 , meaning that $6.8 \%$ of all grid cells were covered by bird surveys. (b) Map of total species richness overlaying all 116 bird species distributions resulting from ensemble models of each species. Dark colours correspond to high species richness (maximum 84 species) and light colours to low species richness. For the different types of protected area, see Figure $\mathrm{S}_{1}$.

Schedule of Protected Species (Council of Agriculture of Executive Yuan 2009) whose update from I April 2009 was used in this study.

\section{Distributional data}

We derived distributional data from a variety of sources to build the first comprehensive distributional dataset of the breeding birds of Taiwan, including data from bird census projects conducted in 1993-2004 (Endemic Species Research Institute unpubl. data), 1999-2003 (Koh et al. 2006a), 2002-2003 (P.-F. Lee unpubl. data), 2003-2004 (Ko 2004; P.-F. Lee unpubl. data), 2006-2007 (Peng 2008), and 2008 (W.-J. Chih, C.-J. Ko \& M.-Y. Yang, unpubl. data) (see the online supplementary material for details). For each record, we entered the following information into the database: (I) species; (2) number of individuals recorded if available, otherwise only presence recorded; (3) day, month and year; (4) geographical coordinates; and (5) sources (see above).

We a priori excluded the White Wagtail Motacilla alba from all analyses because it is not possible to visually distinguish breeding individuals and winter visitors, some of which extend their stay in Taiwan into the breeding season.

To verify the distributional data, records of each species were plotted using ArcGIS and checked for unusual records. First, any record that was outside of Taiwan was deleted. Second, we restricted 
records to the months of March to July, which is the main breeding season of most species, leaving us with 96,783 records among the remaining 144 species.

Third, we examined each sampling point to eliminate unreliable records which were likely erroneous, such as: 1 ) the recorded place name and geographical coordinates were not consistent; 2) the avifauna recorded at a single sampling point was highly unusual for the specific habitat type and elevational range (Wang et al. 1991, Shiu 2003, Fang 2008; W.-J. Chih, pers. comm., pers. obs.); for example, if several farmland species typical of low elevations had been recorded together in mountain forest, we would evaluate all the records of that single sampling point as unreliable and consequently delete them. As a result, we deleted all the records from 28 sampling points (with each point containing several to tens of species). The remaining number of records was 88,646 ( $91.6 \%$ of the original 96,783 records).

For each species, we then coded each 1 x 1 km grid cell as either present (presence recorded $\geq 1$ visit) or absent (absence recorded $\geq 5$ visits). Finally, we excluded those species for which $<30$ grid cells had been coded as present, because distribution models usually do not perform well at low sample sizes (Stockwell and Peterson 2002, Wisz et al. 2008). This left us with 116 species (Appendix S1) with 33,785 presence records within the $I x \perp \mathrm{km}$ grid, and a total of 2,455 grid cells containing presence records of $\geq 1$ species (Figure $1 \mathrm{a}$ )

\section{Combining habitat data with environmental data}

To build distributional models for each bird species, we used 120 environmental data layers compiled by the Spatial Ecology Lab of National Taiwan University (for details, see Lee et al. 1997) which were updated in 2008 by the same lab. These environmental data layers fall in to eight categories and cover the entire mainland of Taiwan with 36,022 IXI km grid cells (Figure 1a), all of which overlay perfectly with each other and the bird distribution grid. We then selected a subset of data layers relevant to the ecology and behaviour of each bird species (sensu Elith and Leathwick 2009; see online supplementary material for details), which resulted in a minimum of 30 to a maximum of 37 data layers associated with each of our 116 species (e.g. 35 in the case of the Taiwan Magpie Urocissa caerulea). To eliminate variables, we first used a two-tailed t-test to test each of the selected environmental variables for significant association with the presence or absence of the species using a $P<0.05$ significance level; only significantly associated variables were retained. We further eliminated variables by running an Unweighted Pair Group Method with Arithmetic Mean (UPGMA) Tree in ENFA to avoid autocorrelation between the remaining variables. If two variables had a correlation coefficient $>0.9$, we retained only one of the two variables, chosen randomly. This elimination procedure resulted in a minimum of nine to a maximum of 25 data layers associated with each of our 116 species (e.g. 17 in the case of the Taiwan Magpie) which we then used to build the distribution models for each species. Further variables were eliminated automatically by the black-box procedures integrated in some of the distribution models described below.

\section{Building distribution models}

To produce one modelled distribution (the 'final map') for each species, we first produced five probabilistic distribution models for each species by using the environmental data layers described above (see also Table $\mathrm{S}_{I}$ and Appendix $\mathrm{S}_{I}$ ) and the following methods: multiple discriminant analysis (MDA) (Johnson and Wichern 1998), logistic regression (LR) (Austin 2002), genetic algorithm for rule-set production (GARP) (Stockwell et al. 2006), ecological niche factor analysis (ENFA) (Hirzel et al. 2002), and maximum-entropy (MAXENT) (Phillips et al. 2006). We built MDA and LR models with SAS 9.o, and GARP, ENFA, MAXENT models with the DesktopGARP software (www.nhm.ku.edu/desktopgarp), Biomapper 3.1 software (www2.unil.ch/biomapper) and maxent 3.3.0 software (www.cs.princeton.edu/ schapire/maxent), respectively (see supplementary material for details). These methods were chosen because several reviews of modelling performance 
had verified the good overall performance of these particular methods (Elith et al. 2006, Hernandez et al. 2006, Guisan et al. 2007, Wisz et al. 2008). Each of these methods was used to model each species's distribution using $50 \%$ of all presence and $50 \%$ of all absence records (training data) and then evaluated with the remaining $50 \%$ of presence and absence records (testing data). Dividing the data randomly into training and testing data is a prerequisite for calculating evaluation metrics such as MaxKappa and the AUC score (Fielding and Bell 1997, Pepe 2000).

Using the AUC score, we ranked the performance of the five models for each species. We then produced an ensemble model for each species using a variant of the frequency histogram method (Figure $\mathrm{I}$ in Araújo and New 2007) by summing up the three best performing models for each species based on their respective AUC scores, thus avoiding over-fitting by eliminating the two worst performing models (M. Araújo in litt. 2012). To add up the three models, we chose the MaxKappa threshold recommended by Freeman and Moisen (2008) to turn the probability surface of each model into a binary presence-absence map (resulting in a distribution map of each species coded $0,1,2$ or 3 ). We then re-coded codes $\mathrm{O}$ and $I$ into absence (o) and codes 2 and 3 into presence ( $I$ ). We chose not to re-code $I$ into presence because we wanted our distribution models to be conservative.

Finally, we deleted over-prediction for 11 of the 116 species by comparing the modelled distributions with published distribution maps (Severinghaus et al. 2010). Over-prediction refers to the distribution model extending into areas where the species has never been observed (e.g. because of interspecific competition, see Discussion). Any region of Taiwan where the species had never been observed was converted into absence by using a variety of appropriate shape files (elevation, ecoregions, counties).

All further analyses were done on these 'final maps' (shown in Appendix $\mathrm{S}_{3}$ ). We calculated the Kappa values of the five models and the final maps of the 116 species based on the observed present (presence recorded $\geq 1$ visit) or absent (absence recorded $\geq 5$ visits) grid cells. Furthermore, we subdivided species into four quartile categories whereby first, second, third and fourth quartile species correspond to the modelled distribution of the respective species covering $0-25 \%$, $25-50 \%, 50-75 \%$ and $75-100 \%$ of all cells of our study area, respectively (corresponding to almost 9,006 cells or 9,006 $\mathrm{km}^{2}$ per quartile). Appendix $\mathrm{S}_{2}$ gives the exact percentage coverage for each species; note that none of the species fell exactly on the $25 \%, 50 \%$ and $75 \%$ dividing line. This categorical measure is called 'range quartile' hereafter.

\section{Protected area coverage of Taiwan}

We used shape files of each of Taiwan's protected areas which were created by the Spatial Ecology Lab of National Taiwan University (Figure SI). These protected areas are categorised into five different types (Forestry Bureau of Council of Agriculture 2011): (1) national parks, (2) nature reserves, (3) forest reserves, (4) wildlife refuges, (5) major wildlife habitats. We further subsumed these five types into three categories: (I) highest protection (national parks only), (2) medium-tohigh protection (all protected areas except major wildlife habitats) and (3) low-to-high protection (all protected areas). Placing national parks into the highest protection category is justified because they cover the largest areas of all protected areas as they must be $>1,000$ ha according to IUCN (2011a) criteria and are overall the best protected by Taiwan's government. We categorised major wildlife habitats into the lowest protection category because they are the only type of protected area that allows people to enter without a government permit.

Taiwan's laws for setting up protected areas predate the establishment of IUCN's (2011a) six protected area categories. Therefore, Taiwan's protected area criteria are somewhat inconsistent with the IUCN criteria. Nevertheless, the Taiwanese government insists that their criteria are sufficient to cover the six types of IUCN criteria. A comparison between these categories and the IUCN categories, published in Chinese (Lee and Chao 2005), suggests that Taiwan's national parks are almost equivalent to IUCN category II, nature reserves are consistent with IUCN category I, forest reserves cover IUCN categories I, IV and VI, wildlife refuges cover IUCN categories I, IV and VI, and major wildlife habitats cover IUCN categories IV and VI. 


\section{Results}

\section{Evaluating model performance}

Overall model performance using mean AUC scores averaged over all species ranked models as follows: MDA, LR, GARP, ENFA, and MAXENT (Table S2). Therefore, our overall model performance falls into the upper half of the AUC interval from 0.7 to 0.9 , which Pearce and Ferrier (2000) labelled as 'reasonable' model performance.

For almost all subcategories (such as endemic species status, conservation status, and so on), MDA was also the best and LR the second best performing technique. GARP and ENFA performed worse than MDA and LR, but better than MAXENT which was the worst performing model in eight out of $I_{4}$ subcategories, and never performed better than third best except for endemic species.

Kappa values decreased in the same order as model performance: from 0.69 for MDA to 0.54 for ENFA (Table S2). We could not obtain Kappa values for Maxent because all the observed grid cells (present or absent) were predicted as present in Maxent. The Kappa value for the final maps (o.69) was equal or better than the five models. Our overall Kappa value falls into the upper half of the Kappa interval from 0.4 to 0.75 , which Landis and Koach (1977) labelled as "good" agreement. For almost all subcategories, Kappa values decreased in the same order as model performance except for the $4^{\text {th }}$ quartile of range quartile rarity where the Kappa value for ENFA was higher than GARP. The Kappa values of each of the final maps of the 116 species are shown in Appendix $\mathrm{S}_{3}$.

\section{Status of Taiwanese breeding birds}

Appendices $S_{1}$ and $S_{2}$ list all 145 recognised breeding bird species of Taiwan (Fang 2008, Chinese Wild Bird Federation 2010). Seventeen species have full endemic status, while 62 belong to a recognised endemic subspecies. Only two species are listed as globally threatened: Fairy Pitta Pitta nympha and Taiwan Bulbul Pycnonotus taivanus which are 'Vulnerable' and five as 'Near Threatened' (IUCN 2011b). However, more species are considered threatened within Taiwan: five are listed as endangered (Australasian Grass-Owl Tyto longimembris, Black Eagle Ictinaetus malayensis, Mountain Hawk-Eagle Nisaetus nipalensis, Black-naped Oriole Oriolus chinensis, and Russet Sparrow Passer rutilans); 33 as rare and valuable, and II as conservation-dependent species. In all, 26, 30 and 89 species were recorded as rare, uncommon and common, respectively. Considering range quartile, 22, 50, 35 and 9 species fell into the first, second, third and fourth quartiles, respectively.

\section{Coverage of species modelled distributions by protected areas}

Protected areas cover $19.25 \%$ of mainland Taiwan, and the five different types (namely, national parks, nature reserves, forest reserves, wildlife refuges, and major wildlife habitats) cover $8.63 \%$, $1.80 \%, 0.59 \%$, $0.71 \%$, and $9.06 \%$, respectively (these percentages do not add to $19.25 \%$ because in a few cases two or more categories of protected areas overlap). Most protected areas in Taiwan are found at mid-elevation (Figure 2), but there is also a peak at the lowest elevation which results from the existence of some coastal protected areas (Figure $\mathrm{ib}$ ).

Overall, $29.8 \%$ of the distributional ranges of the 116 modelled species are covered by Taiwanese protected areas (Table I). This percentage drops to $16.9 \%$ for medium-to-high protected areas and to $12.5 \%$ for national parks. Looking at species of global or Taiwanese conservation concern, coverage of protected species ranges from $17.0 \%$ to $46.7 \%$ for all protected areas, but this drops to from $5.8 \%$ to $20.6 \%$ for national parks. Coverage of non-threatened species is $27.0 \%$ to $29.6 \%$ for all protected areas, but drops to $11.5 \%$ to $12.5 \%$ for national parks.

There is an inverse relationship between the degree of conservation status and coverage by protected areas, for both global and Taiwanese conservation status (Table 1 ). The situation is 


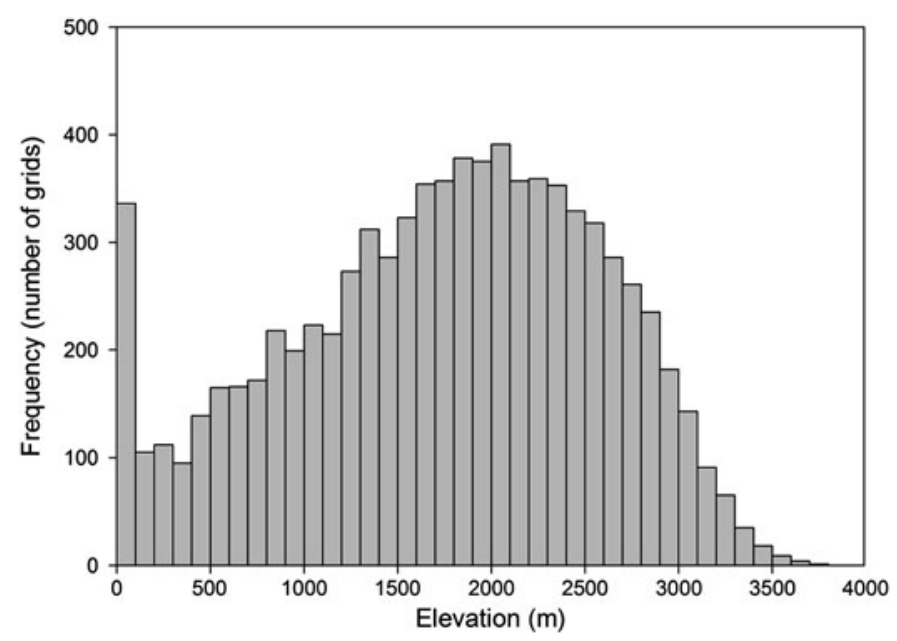

Figure 2. Number of grid cells $(n=8,240)$ of Taiwan's protected areas falling into various elevational bands.

reversed for endemic species, whereby endemic species are best covered, followed by endemic subspecies and then non-endemic species. Finally, for range quartile, we find a slightly different pattern, with decreasing coverage from the first to the third quartile but then slightly increased coverage for the fourth quartile.

The relationship between the percentage of each species's coverage of our study area and the percentage of that species's distribution covered by protected areas (Figure 3) clearly shows that there is an upper boundary for species well covered by protected areas, but also that there are many species not well covered by protected areas at all (see Appendix $\mathrm{S}_{2}$ and Table $\mathrm{S}_{3}$ ). We categorised those species whose distributions are covered by $<5 \%$ by the highest protection category as 'badly protected.' We chose this $5 \%$ threshold because it is about one-eighth of the coverage of species with the highest cover and it encompasses about one-third (40 out of 116) of all species; using a higher threshold would have included too many species. In this case, there is no need to consider the other protection categories, as the percentage cover of all three categories are highly correlated across species (linear regression for highest versus medium-to-high: $n=116, F=6,021.9, r^{2}=0.98$, $P<0.0001$; for highest versus low-to-high: $n=116, F=4,397.9, r^{2}=0.98, P<0.0001$; for medium-tohigh versus low-to-high: $\left.n=116, F=29,882.9, r^{2}=1.00, P<0.0001\right)$. Therefore, essentially the same species would be 'badly protected' regardless of which protection category we chose.

\section{Comparing range quartile, Taiwanese conservation and endemic status}

Comparing range quartile with endemic species status, we found that no endemic species is a fourth quartile species, while endemic subspecies are found in all four quartiles (Figure 4). Comparing range quartile with Taiwanese conservation status (Figure 5), we found an overall agreement between these two measures, with endangered species found only in the first quartile, and other conservation-dependent species found in all quartiles except the fourth. Rare and valuable species appear in all quartiles, but at a much higher percentage in the first and second quartiles. Similarly, the four categories of Taiwanese conservation status are related to the number of grid cells where the respective species were recorded and predicted, with these rankings being significantly different from being equal (Table 2; Kruskal-Wallis, $\mathrm{df}=3 ; n=144, H=34.40, P<0.0001$, $n=116, H=15.98, P=0.001$ and $n=116, H=9.08, P=0.03$, respectively). The latter analyses demonstrate that the Taiwanese conservation categories correspond, as would be expected, to the 
Table 1. Percentage cover of the distribution of 116 modelled species by the protected areas of Taiwan, classified into three categories (see Methods). In each cell, we first give the mean percentage \pm SD, then the $95 \%$ confidence interval range in brackets. For definitions of categories in column 1, see Appendices $\mathrm{S}_{1}$ and $\mathrm{S}_{2}$.

\begin{tabular}{|c|c|c|c|c|}
\hline Category & $\begin{array}{l}\text { Sample } \\
\text { size }\end{array}$ & Highest protection & $\begin{array}{l}\text { Medium-to-high } \\
\text { protectiona }^{\text {a }}\end{array}$ & $\begin{array}{l}\text { Low-to-high } \\
\text { protection }\end{array}$ \\
\hline \multicolumn{5}{|l|}{$\begin{array}{l}\text { Taiwanese conservation } \\
\text { status }\end{array}$} \\
\hline Endangered & 1 & 5.8 & 14.0 & $27 \cdot 5$ \\
\hline Rare and valuable & 19 & $12.9 \pm 7.3(9.4-16.5)$ & $18.3 \pm 9.4(13.8-22.9)$ & $32.6 \pm 18.4(23.8-41.5)$ \\
\hline $\begin{array}{l}\text { Other conservation- } \\
\text { dependent species }\end{array}$ & 11 & $20.6 \pm 11.6(12.8-28.4)$ & $26.0 \pm 12.5(17.6-34.4)$ & $46.7 \pm 23.9(30.6-62.7)$ \\
\hline Non-threatened & 85 & $11.5 \pm 9.6(9.4-13.5)$ & $15.4 \pm 11.6(12.9-17.9)$ & $27.0 \pm 22.0(22.2-31.7)$ \\
\hline \multicolumn{5}{|l|}{ IUCN Conservation Status } \\
\hline 'Vulnerable' & 1 & 7.2 & 14.0 & 17.0 \\
\hline 'Near Threatened' & 4 & $15.4 \pm 6.4(5.1-25.6)$ & $21.1 \pm 7.5(9.2-33.0)$ & $37.8 \pm 15.4(13 \cdot 3-62.3)$ \\
\hline 'Least Concern' & 111 & $12.5 \pm 9.9(10.6-14.3)$ & $16.7 \pm 11.8(14.5-19.0)$ & $29.6 \pm 22.4(25.4-33.8)$ \\
\hline \multicolumn{5}{|l|}{ Endemism } \\
\hline Endemic Species & 16 & $18.7 \pm 9.4(13.7-23.7)$ & $24.6 \pm 9.6(19.5-29.7)$ & $43.8 \pm 18.8(33.8-53.8)$ \\
\hline Endemic Subspecies & 53 & $15.1 \pm 9.8(12.4-17.8)$ & $19.9 \pm 11.4(16.7-23.0)$ & $35.6 \pm 21.4(29.7-41.5)$ \\
\hline Non-endemic & 47 & $7 \cdot 5 \pm 7.5(5 \cdot 3-9 \cdot 7)$ & $10.8 \pm 9.7(8.0-13.7)$ & $18.4 \pm 18.9(12.8-23.9)$ \\
\hline \multicolumn{5}{|l|}{ Recorded rarity } \\
\hline Rare & 6 & $18.4 \pm 12.8(5.0-31.8)$ & $24 \cdot 3 \pm 14.2(9.4-39 \cdot 3)$ & $45.6 \pm 27.2(17.0-74.2)$ \\
\hline Uncommon & 23 & $14.9 \pm 7.3(11.7-18.0)$ & $20.7 \pm 9.3(16.6-24.7)$ & $37.2 \pm 18.1(29.4-45.0)$ \\
\hline Common & 87 & $11.5 \pm 10.0(9.4-13.6)$ & $15.4 \pm 11.8(12.8-17.9)$ & $26.7 \pm 22.1(22.0-31.4)$ \\
\hline \multicolumn{5}{|l|}{ Range quartile } \\
\hline $1^{\text {st }}$ quartile $(0-25 \%)$ & 22 & $16.6 \pm 15.6(9.7-23.5)$ & $20.6 \pm 17.4(12.9-28.3)$ & $36.5 \pm 32.7(22.0-50.9)$ \\
\hline $2^{\text {nd }}$ quartile $(25-50 \%)$ & 50 & $13.0 \pm 9.1(10.4-15.6)$ & $17.9 \pm 11.8(14.5-21.3)$ & $32.0 \pm 22.6(25.5-38.4)$ \\
\hline $3^{\text {rd }}$ quartile $(50-75 \%)$ & 35 & $9.8 \pm 5.6(7.8-11.7)$ & $13.7 \pm 7.1(11.3-16.1)$ & $23.6 \pm 13.4(19.0-28.2)$ \\
\hline $4^{\text {th }}$ quartile $(75-100 \%)$ & 9 & $10.4 \pm 2.5(8.5-12.3)$ & $14.4 \pm 2.8(12.2-16.6)$ & $25.1 \pm 5.1(21.2-29.0)$ \\
\hline All species & 116 & $12.5 \pm 9.8(10.7-14.3)$ & $16.9 \pm 11.7(14.7-19.0)$ & $29.8 \pm 22.2(25.7-33.8)$ \\
\hline
\end{tabular}

total area in which the species was recorded and predicted to be present. However, there are a number of species which fall outside of these general trends (see below).

\section{Species whose status may be reassessed}

Using the analyses above, we identified those species whose status may need to be reassessed because of possible conflicts between the respective conservation-relevant measures (Table $\mathrm{S}_{3}$ ). As with any categorisation, we made some arbitrary decisions about how to categorise species. For example, we only considered first quartile species to be threatened because of a small distributional range, or we categorised those species whose distributions had $<5 \%$ cover by the highest protection category as 'badly protected' (see above). Nevertheless, we considered these categories as helpful to focus attention on those species that may need to be reassessed most urgently. While the process of classifying a species's conservation status has become more and more formalised (Mace et al. 2008), this process still includes some arbitrary categorisations. Therefore, the examples below are not meant as descriptive recommendations, but as suggestive pointers as to which species should be further investigated and why.

Category 1: Species of limited distribution and protection: 10 species are all first quartile species and $<5 \%$ of their distributions are protected. Only four of these have a Taiwanese conservation status of rare and valuable (Ring-necked Pheasant Phasianus colchicus, Greater Painted-snipe Rostratula benghalensis, Collared Scops-owl Otus lettia, Crested Myna Acridotheres cristatellus) and one of conservation-dependent (Oriental Pratincole Glareola maldivarum). The remaining 


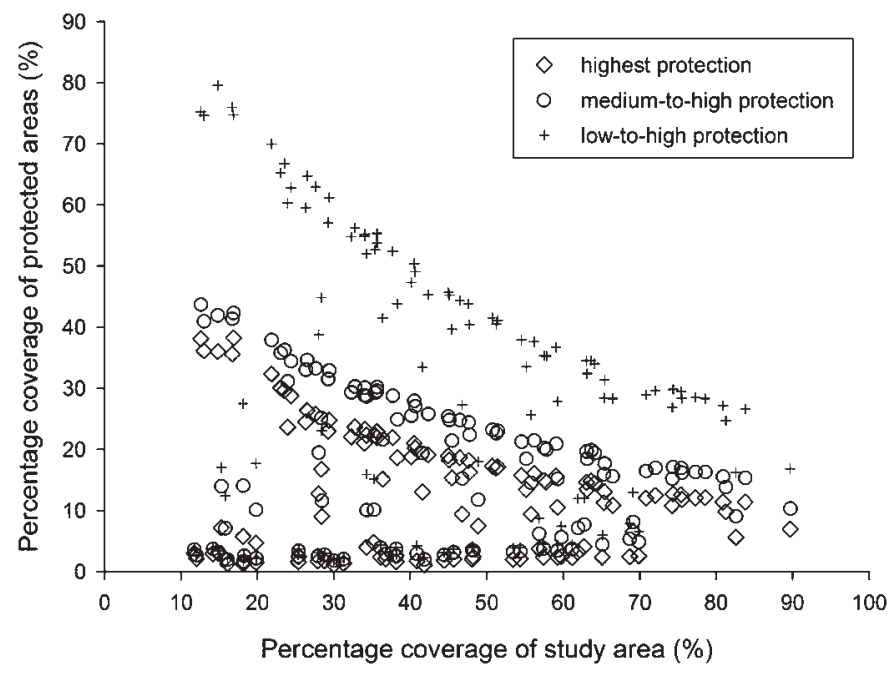

Figure 3. Relationship between the percentage of each species's coverage of our study area (mainland Taiwan) and the percentage of that species's distribution covered by the highest, medium-tohigh, and low-to-high levels of protection.

five species (Yellow Bittern Ixobrychus sinensis, Cinnamon Bittern I. cinnamomeus, Malayan Night-Heron Gorsachius melanolophus, Ruddy-breasted Crake Porzana fusca, and Black-billed Magpie Pica pica) deserve special attention.

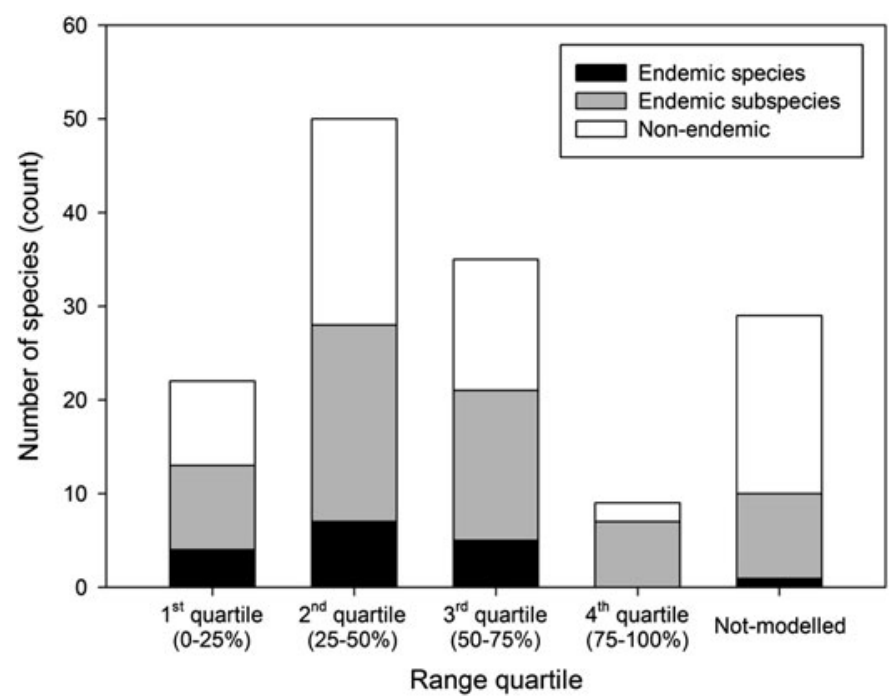

Figure 4. Comparison of Taiwanese endemic status (see Appendix $\mathrm{S}_{1}$ ) versus range quartile (see Appendix S2). Quartiles 1-4 correspond to the percentage coverage of the study area by each species (see Methods). 'Not modelled' means the sample size was insufficient to model the species's distribution (see Methods and Appendix SI). The distribution of endemic status categories is not distributed randomly amongst the four categories of range quartile (likelihood ratio chi-square $\left.G^{2}=5.04, \mathrm{df}=6, n=116, P=0.54\right)$. 


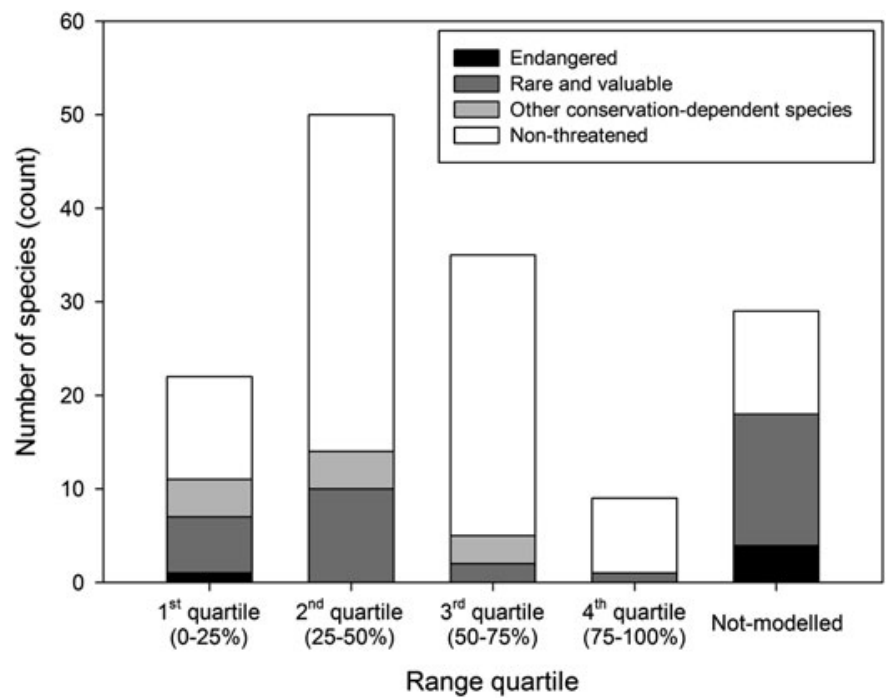

Figure 5. Comparison of Taiwanese conservation status (see Appendix SI) versus range quartile (Appendix S2). Quartiles $1-4$ correspond to the percentage coverage of the study area by each species (see Methods). 'Not modelled' means the sample size was insufficient to model the species's distribution (see Methods and Appendix $\mathrm{S}_{1}$ ). The distribution of conservation status categories is not significantly different from random (likelihood ratio chi-square $G^{2}=12.74$, $\mathrm{df}=9, n=116, P=0.17)$.

Category 2: Species of limited distribution: There remain 12 first quartile species. Except for the Black Eagle, Gray-faced Woodpecker Picus canus and White-browed Bush-Robin Tarsiger indicus, they were all recorded as common by the Chinese Wild Bird Federation (2010). As the definition

Table 2. Mean, median and range of recorded and predicted grid cells for four different categories of Taiwanese conservation status (Appendix S1) for all breeding species $(n=144)$ and all modelled breeding species $(n=116)$. Recorded cells are those where a species was recorded in our database, and predicted cells are those where a species was predicted to be present in our final maps.

\begin{tabular}{|c|c|c|c|c|c|c|}
\hline \multirow{3}{*}{$\begin{array}{l}\text { Taiwanese } \\
\text { conservation } \\
\text { status }\end{array}$} & \multirow{2}{*}{\multicolumn{2}{|c|}{$\begin{array}{l}\text { Breeding species } \\
\begin{array}{l}\text { Number of grid } \\
\text { cells recorded }\end{array} \\
\end{array}$}} & \multicolumn{4}{|c|}{ Modelled breeding species } \\
\hline & & & \multicolumn{2}{|c|}{$\begin{array}{l}\text { Number of grid } \\
\text { cells recorded }\end{array}$} & \multicolumn{2}{|c|}{$\begin{array}{l}\text { Number of grid } \\
\text { cells predicted }\end{array}$} \\
\hline & Mean $(n)$ & $\begin{array}{l}\text { Median } \\
\text { (range) }\end{array}$ & Mean (n) & $\begin{array}{l}\text { Median } \\
\text { (range) }\end{array}$ & Mean $(n)$ & $\begin{array}{l}\text { Median } \\
\text { (range) }\end{array}$ \\
\hline $\begin{array}{l}\text { Endangered } \\
\text { (EN) }\end{array}$ & $12.0(5)$ & $9(3-30)$ & $30.0(1)$ & 30 & $6,516.0(1)$ & 6,516 \\
\hline $\begin{array}{l}\text { Rare and } \\
\text { valuable } \\
\text { (RV) }\end{array}$ & $81.3(33)$ & $43(1-555)$ & $132.0(19)$ & $86(30-555)$ & $13,099.2(19)$ & $12,262(5,500-27,166)$ \\
\hline $\begin{array}{l}\text { Other } \\
\text { conservation- } \\
\text { dependent } \\
\text { species (CD) }\end{array}$ & $158.5(11)$ & $124(47-359)$ & 158.5 (II) & $124(47-359)$ & $12,456.8$ (11) & $12,350(5,333-21,277)$ \\
\hline $\begin{array}{l}\text { Non-threatened } \\
\text { (NT) }\end{array}$ & $312.1(95)$ & $185(0-1,204)$ & $347.1(85)$ & $213(33-1,204)$ & $17,015.3(85)$ & $16,443(4,229-32,308)$ \\
\hline
\end{tabular}


of common is "the respective bird species was recorded in $>70 \%$ of suitable habitats" (Appendix S2), we suggest that these suitable habitats may be relatively rare within the study area. Furthermore, while six of these species are categorised as threatened in Taiwan, another six species are considered non-threatened (Spotted Nutcracker Nucifraga caryocatactes, Taiwan Bush-Warbler Bradypterus alishanensis, Grey-hooded Fulvetta Alcippe cinereiceps, Winter Wren Troglodytes troglodytes, Collared Bush-Robin Tarsiger johnstoniae and Vinaceous Rosefinch Carpodacus vinaceus); given their restricted distributions, their status may need to be reassessed. Finally, all of these species except the Black Eagle and the Gray-faced Woodpecker are endemic species or endemic subspecies, further emphasising their conservation value.

Category 3: Species of limited protection: There remain another 30 species whose distributions are protected by $<5 \%$. All of these are either second or third quartile species, and they are also all recorded as common, except the Emerald Dove Chalcophaps indica and Golden-headed Cisticola Cisticola exilis which were recorded as uncommon. Meanwhile, the Taiwan Magpie Urocissa caerulea, albeit recorded as common, is a conservation-dependent and second quartile species. More protected areas may need to be established for these three species.

Category 4: Species which may need to be reassessed: Here we summarise species whose assessment categories are not in agreement. The Taiwan Partridge Arborophila crudigularis is considered uncommon and conservation-dependent but is a third quartile species. The Crested Serpent-Eagle Spilornis cheela and Crested Goshawk Accipiter trivirgatus are considered rare and valuable species but are recorded as common and are a fourth and third quartile species, respectively. The Mountain Scops-Owl Otus spilocephalus is considered a rare and valuable species but is recorded as common and a third quartile species. The Plumbeous Water-redstart Rhyacornis fuliginosa is considered conservation-dependent but is recorded as common and a third quartile species. The White-tailed Robin Cinclidium leucurum is recorded as uncommon and considered conservation-dependent but is a third quartile species. The Green-backed Tit Parus monticolus and the Taiwan Barwing Actinodura morrisoniana are considered conservation-dependent but are recorded as common and second quartile species. Another II species are recorded as common while being only second quartile species. All of these species may need to be reassessed.

\section{Discussion}

Ideally, a distribution model of a biological species should be a geographic representation of its ecological niche (Peterson et al. 2011). Because the data to build the model can only come from the species's realised niche, the model should represent the realised niche, but may also extend into the species's fundamental niche. This can be a desirable feature, e.g. to predict into which areas invasive species may spread (Gallien et al. 2012, Václavík and Meentemeyer 2012) or where a new population of an endangered species may be introduced (Pérez et al. 2011).

However, in some cases, distribution models over-predict the distribution of a species because they do not take into account factors that limit the realised niche, e.g. interspecific competition. For example, the Light-vented Bulbul Pycnonotus sinensis and the Taiwan Bulbul are sister species which hybridise along their contact zone within Taiwan, with each species probably being excluded from the range of the other by interspecific competition (Severinghaus et al. 2010). Therefore, it is to be expected that the modelled distribution of the Light-vented Bulbul incorporates the modelled distribution of the Taiwan Bulbul, and vice versa. To deal with this obvious problem in 11 of our species, we corrected over-prediction by cutting out regions where the species had never been observed (previously done, e.g. for migratory birds, see Walther et al. 2004, Walther et al. 2007, Wisz et al. 2007, Walther et al. 2010).

Given that our distribution models are based on the most comprehensive avian database of Taiwan, and are the first to be based on an ensemble approach and to correct for over-prediction, and have yielded reasonable AUC scores, our distribution maps of Taiwanese birds (Appendix $\mathrm{S}_{3}$ ) are currently the best available. There is ongoing discussion about both the best evaluation metrics (Fielding and Bell 1997, Pepe 2000, Anderson et al. 2003, Austin et al. 2006, Lobo et al. 2008, 
Liu et al. 2009) for evaluating model performance, as well as the best thresholds for converting probabilistic into binary maps (Manel et al. 2001, Liu et al. 2005, Hernandez et al. 2006, JiménezValverde and Lobo 2007, Pearson et al. 2007, Freeman and Moisen 2008, Nenzén and Araújo 2011, Bean et al. 2012). Our study was not designed to answer these questions, but we tried to minimise any concerns by combining ensemble modelling with the AUC evaluation technique and the MaxKappa threshold.

These maps allowed us to calculate the protected area coverage of Taiwan's bird species, which is major improvement in assessing the status of each species status as well as the overall performance of the protected area network in maintaining the long-term survival of Taiwan's avifauna. Currently, Taiwan's protected areas cover almost $30 \%$ of the distributional ranges of the 116 bird species that we modelled. However, this figure dropped to $16.9 \%$ for areas with medium-to-high and to $12.5 \%$ for the highest protection (Table 1 ).

Species with low protected area coverage (Appendix S2, Figure 3) should be of special concern which is why we point them out for reassessment (Table $\mathrm{S}_{3}$ ). Of course, some of these 'badly' protected species survive well in human-modified landscapes, e.g. Malayan Night-Heron and Black-billed Magpie (both category 1 species; Table $S_{3}$ ), and are therefore hardly dependent on natural landscapes found in protected areas for long-term survival. None of the five criteria used to evaluate each species's status from the Directions for Evaluating Wildlife Categories (see Methods) so far considers either the protected area coverage (this study) or the percentage human-modified landscape covered by the species's distribution (see Discussion below), although the fifth criterion incorporates the rate of habitat loss. Therefore, the use of GIS mapping could enhance the Wildlife Conservation Advisory Committee's ability to categorise objectively the status of Taiwan's bird species (as well as other taxa).

Given that we now have distribution maps of each bird species, we could also quantify the amount of human-modified versus natural landscapes used by each bird species through overlay analyses. However, we first have to define which habitats are more or less modified by humans which would require more expert consultation and research (such as by quantifying the human appropriation of net primary production, e.g. Haberl et al. 2010).

Our distribution maps have another benefit, i.e. a more realistic estimate of the area occupied by a species, which we then divided into four quartiles in accordance with other macroecological studies (Jetz and Rahbek 2002, Wisz et al. 2007). The size of a species's distribution is per se an important criterion for determining conservation status because smaller occupied areas are at larger risk of being subject to catastrophes droughts, fires, epidemics, etc; e.g., Mace and Lande 1991), regardless of how much of the occupied area overlaps with protected areas, natural or human-modified habitats.

Based on our modelled distributions, we investigated how categories of conservation status and endemism established by the Wildlife Conservation Advisory Committee relate to each species's occupied area and range quartile. As one might expect, no relationship was found between range quartile and endemic status (Figure 4) indicating that endemic species and subspecies range from narrowly to widely distributed species. Also as expected, we found that a general relationship exists between range quartile and conservation status with narrowly distributed birds being overall more endangered (Table 2, Figure 5). However, there is considerable variation in range quartile among the categories of Taiwanese conservation status, with some first quartile species considered non-threatened and some fourth quartile species considered rare and valuable (Figure 5). Likewise, the numerical ranges of predicted cells among the categories of Taiwanese conservation status (Table 2) suggest that there are species whose status may need to be reassessed.

To help with such a reassessment, we here made an initial attempt to select those species that, based on range quartile and protected area coverage, may be more threatened by local or national extinction than previously realised (Table $S_{3}$ ). While such species may need to be uplisted, we also pointed out a number of species which could be downlisted (e.g. threatened species that are recorded as common and are in the fourth quartile). We refrain from making definite recommendations here because (I) additional criteria, as stated in the Directions for Evaluating Wildlife Categories, need to be considered and (2) our suggested criteria have not 
yet been accepted by the Wildlife Conservation Advisory Committee. Therefore, they only remain recommendations for the moment. Further discussion of this complex topic is provided in Walther et al. (2011).

As pointed out above, our cut-off points for including species in Table $\mathrm{S}_{3}$ were arbitrary. For example, first quartile species in our study have a distribution of $<9,006 \mathrm{~km}^{2}$ (see Methods), while the cut-off points for Endangered and Vulnerable species under the IUCN criteria are 5,000 $\mathrm{km}^{2}$ and $20,000 \mathrm{~km}^{2}$, respectively (Mace et al. 2008). There are only four species (Cinnamon Bittern, Black-billed Magpie, Winter Wren, Vinaceous Rosefinch) with a distribution of $<5,000 \mathrm{~km}^{2}$ in our assessment but 79 species with a distribution of $<20,000 \mathrm{~km}^{2}$ (Appendix $\mathrm{S}$ I) while 22 species are first quartile species. Any of these cut-off points is as justifiable as any other; however, 22 species represents about $19 \%$ of the 116 modelled species which seems a more reasonable cut-off point than $3 \%$ or $68 \%$ which would have resulted from using the IUCN criteria. We therefore chose to keep to with our own cut-off criterion of first quartile species.

Finally, our distribution maps allow us to pinpoint sampling gaps both within and outside of protected areas, which should be subject to further fieldwork, for example, much of Taiwan's central mountain range which has almost no records but is predicted to have high species richness (Figure $1 \mathrm{a}, \mathrm{Ib}$ ). Better data coverage will result in even better models, which in turn will result in even better conservation assessments.

We recommend that the species' potential distribution (measured continuously as the number of predicted cells, and categorically as the range quartile) and the protected area coverage be incorporated into future assessments of the status of Taiwanese birds, and that assessments of current and future land-use and threats from climate change, direct persecution and invasive species should also be considered.

\section{Supplementary Material}

The supplementary materials for this article can be found at journals. cambridge.org/bci

\section{Acknowledgements}

The authors thank Wen-Jay Chih, Chie-Jen Ko, Chun-Yi Peng and Mang-Yu Yang for providing additional distribution data, Wen-Jay Chih for comments on bird status, Tzu-Hsin Yang for comments on Taiwan's protected areas, Miguel Araújo, Morgane Barbet-Massin, Falk Hüttmann, Frédéric Jiguet, Cheng-En Li, Steffan Oppel, Wilfried Thuiller, I-Hui Wu and one anonymous referee for comments on modelling species distributions. This work was partially supported by National Park Division of the Construction and Planning Agency, Ministry of the Interior, Taiwan and the National Science Council, Taiwan under grants NSC 97-2321-B-002-032, NSC 99-2621-B-oo2-003, NSC 99-2811-B-329-001, NSC 99-2321-B-329-001-MY2, and NSC 101-2631-H-002-005.

\section{References}

Anderson, R. P., Lew, D. and Peterson, A. T. (2003) Evaluating predictive models of species' distributions: criteria for selecting optimal models. Ecol. Model. 162: 211-232.

Araújo, M. B. and New, M. (2007) Ensemble forecasting of species distributions. Trends Ecol. Evol. 22: 42-47.

Austin, M. P. (2002) Spatial prediction of species distribution: An interface between ecological theory and statistical modelling. Ecol. Modell. 157: 101-118.

Austin, M. P., Belbin, L., Meyers, J. A., Doherty, M. D. and Luoto, M. (2006) Evaluation of statistical models used for predicting plant species distributions: Role of artificial data and theory. Ecol. Model. 199: 197-216.

Barbet-Massin, M., Walther, B. A., Thuiller, W., Rahbek, C. and Jiguet, F. (2009) Potential impacts of climate change on the winter 
distribution of Afro-Palaearctic migrant passerines. Biol. Lett. 5: 248-251.

Bean, W. T., Stafford, R. and Brashares, J. S. (2012) The effects of small sample size and sample bias on threshold selection and accuracy assessment of species distribution models. Ecography 35: 250-258.

Chinese Wild Bird Federation (2010) The checklist of the birds of Taiwan. Feather 23: 66-95. (In Chinese).

Council of Agriculture of Executive Yuan (2009) Schedule of protected species. Taipei, Taiwan: Council of Agriculture of Executive Yuan. (In Chinese).

Elith, J., Graham, C. H., Anderson, R. P., Dudík, M., Ferrier, S., Guisan, A., Hijmans, R. J., Huettmann, F., Leathwick, J. R., Lehmann, A., Li, J., Lohmann, L. G., Loiselle, B. A., Manion, G., Moritz, C., Nakamura, M., Nakazawa, Y., Overton, McC., J., Peterson, A. T. and Phillips, S. J. (2006) Novel methods improve prediction of species' distributions from occurrence data. Ecography 29: 129-151.

Elith, J. and Leathwick, J. (2009) The contribution of species distribution modelling to conservation prioritization. Pp. 70-93 in A. Moilanen, K.A. Wilson and H. P. Possingham, eds. Spatial conservation prioritization quantitative methods and computational tools. New York: Oxford University Press.

Fang, W.-H. (2008) The complete field guide of the birds of Taiwan. Taipei, Taiwan: Owl Publishing House Co., Ltd. (In Chinese).

Fielding, A. H. and Bell, J. F. (1997) A review of methods for the assessment of prediction errors in conservation presence/absence models. Environ. Conserv. 24: 38-49.

Forestry Bureau of Council of Agriculture (2011) Nature conservation website. Taipei: Forestry Bureau, Council of Agriculture. http://conservation.forest.gov.tw/ mp.asp?mp=11 (accessed October, 2011)

Freeman, E. A. and Moisen, G. G. (2008) A comparison of the performance of threshold criteria for binary classification in terms of predicted prevalence and kappa. Ecol. Modell. 217: 48-58.

Gallien, L., Douzet, R., Pratte, S., Zimmermann, N. E. and Thuiller, W. (2012) Invasive species distribution models - how violating the equilibrium assumption can create new insights. Global Ecol. Biogeogr. 21: 1126-1136.
Guisan, A., Zimmermann, N. E., Elith, J., Graham, C. H., Phillips, S. and Peterson, A. T. (2007) What matters for predicting the occurrences of trees: Techniques, data, or species' characteristics? Ecol. Monogr. 77: 615-630.

Haberl, H., Erb, K.-H. and Krausmann, F. (Lead author); McGinley, M. (Topic Editor) (2010) Global human appropriation of net primary production (HANPP). In: C. J. Cleveland, ed. Encyclopedia of earth. Washington DC: Environmental Information Coalition, National Council for Science and the Environment. http://www.eoearth. org/article/Global_human_appropriation_ of_net_primary_production_(HANPP) (accessed March, 2012)

Hernandez, P. A., Graham, C. H., Master, L. L. and Albert, D. L. (2006) The effect of sample size and species characteristics on performance of different species distribution modelling methods. Ecography 29: 773-785.

Hirzel, A. H., Hausser, J., Chessel, D. and Perrin, N. (2002) Ecological-niche factor analysis: How to compute habitat-suitability maps without absence data? Ecology 83: 2027-2036.

Hsu, F.-H., Yao, C.-T., Lin, S. R.-S., Yang, C.-C. and Lai, S.-J. (2004) Avian species composition and distribution along elevation gradient in the Southern Taiwan. Endemic Species Res. 6: 41-66. (In Chinese).

IUCN (2011a) Guidelines for protected area management categories. http://www.unepwcmc.org/protected_areas/categories/eng/ c3.htm (accessed May, 2011)

IUCN (2011b) The IUCN Red List of threatened species. http://www.iucnredlist.org/ (accessed March, 201I)

Jetz, W. and Rahbek, C. (2002) Geographic range size and determinants of avian species richness. Science 297: 1548-1551.

Jiménez-Valverde, A. and Lobo, J. M. (2007) Threshold criteria for conversion of probability of species presence to either-or presenceabsence. Acta Oecol. 31: 361-369.

Johnson, R. A. and Wichern, D. W. (1998) Applied multivariate statistical analysis. Upper Saddle River, NJ: Prentice-Hall International.

Ko, C.-J. (2004) The relationship between avian community and forest landscapes in Guanwu, Taiwan. Master's thesis. National Taiwan University. (In Chinese). 
Ko, C.-Y., Lee, P.-F., Bai, M.-L. and Lin, R.-S. (2009a) A rule-based species predictive model for the vulnerable Fairy Pitta (Pitta nympha) in Taiwan. Taiwania 54: 28-36.

Ko, C.-Y., Lin, R.-S., Ding, T.-S., Hsieh, C.-H. and Lee, P.-F. (2009b) Identifying biodiversity hotsopts by predictive models: A case study using Taiwan's endemic bird species. Zool. Stud. 48: 418-431.

Koh, C.-N., Lee, P.-F. and Lin, R.-S. (2006a) Bird species richness patterns of northern Taiwan: Primary productivity, human population density, and habitat heterogeneity. Diversity Distrib. 12: 546-554.

Koh, C.-N., Lee, P.-F. and Wu, S.-H. (2006b) Does the distribution of breeding bird species richness in Taiwan follow the mid-domain effect? Taiwania 51: 108-116.

Landis, J. R. and Koch, G. G. (1977) The measurement of observer agreement for categorical data. Biometrics 33: 159-174.

Lee, L.-L. and Chao, J.-T. (2005) Analysis and evaluation of status and management of protected areas in Taiwan. Taipei, Taiwan: Forestry Bureau of Council of Agriculture of Executive Yuan. (In Chinese).

Lee, P.-F., Ding, T.-S., Hsu, F.-H. and Geng, S. (2004) Breeding bird species richness in Taiwan: Distribution on gradients of elevation, primary productivity and urbanization. J. Biogeogr. 31: 307-314.

Lee, P.-F., Liao, C.-Y., Lee, Y.-C., Pan, Y.-H., Fu, W.-H. and Chen, H.-W. (1997) An ecological and environmental GIS database for Taiwan. Taipei, Taiwan: Department of Zoology, National Taiwan University. (In Chinese).

Liu, C., Berry, P. M., Dawson, T. P. and Pearson, R. G. (2005) Selecting thresholds of occurrence in the prediction of species distributions. Ecography 28: 385-393.

Liu, C., White, M. and Newell, G. (2009) Measuring the accuracy of species distribution models: a review. In Proceedings of the 18th World IMACS / MODSIM Congress, Cairns, Australia, 13-17 July 2009.

Lobo, J. M., Jiménez-Valverde, A. and Real, R. (2008) AUC: a misleading measure of the performance of predictive distribution models. Global Ecol. Biogeogr. 17: 145-151.

Mace, G. M., Collar, N. J., Gaston, K. J., HiltonTaylor, C., AkÇAkaya, H. R., Leader-Williams, N., Milner-Gulland, E. J. and Stuart, S. N.
(2008) Quantification of extinction risk: IUCN's system for classifying threatened species. Conserv. Biol. 22: 1424-1442.

Mace, G. M. and Lande, R. (1991) Assessing extinction threats: Toward a reevaluation of IUCN threatened species categories. Conserv. Biol. 5: 148-157.

Manel, S., Williams, H. C. and Ormerod, S. J. (200I) Evaluating presence-absence models in ecology: the need to account for prevalence. J. Appl. Ecol. 38: 921-931.

Nenzén, H. K. and Araújo, M. B. (2011) Choice of threshold alters projections of species range shifts under climate change. Ecol. Modell. 222: 3346-3354.

Pearce, J. and Ferrier, S. (2000) Evaluating the predictive performance of habitat models developed using logistic regression. Ecol. Modell. 133: 225-245.

Pearson, R. G., Raxworthy, C. J., Nakamura, M. and Peterson, A. T. (2007) Predicting species distributions from small numbers of occurrence records: a test case using cryptic geckos in Madagascar. J. Biogeogr. 34: 102-117.

Peng, C.-Y. (2008) Temporal and spatial variations of bird assemblage in the Taroko National Park. Master's thesis. National Taiwan University. (In Chinese).

Pepe, M. S. (2000) An interpretation for the ROC curve and inference using GLM procedures. Biometrics 56:352-359.

Pérez, I., Noguera, J. C. and Mínguez, E. (2011) Is there enough habitat for reintroduced populations of the Lesser Kestrel? A case study in eastern Spain. Bird Conserv. Intenatn. 21: 228-239.

Peterson, A. T., Soberón, J., Pearson, R. G., Anderson, R. P., Martínez-Meyer, E., Nakamura, M. and Araújo, M. B. (2011) Ecological niches and geographic distributions. Princeton, NJ: Princeton University Press.

Phillips, S. J., Anderson, R. P. and Schapired, R. E. (2006) Maximum entropy modelling of species geographic distributions. Ecol. Modell. 190: 231-259.

Severinghaus, L. L., Ding, T.-S., Fang, W.-H., Lin, W.-H., Tsai, M.-C. and Yen, C.-W. (2010) The avifauna of Taiwan. Taipei, Taiwan: Forestry Bureau of Council of Agriculture of Executive Yuan. (In Chinese). 
Shiu, H.-J. (2003) Spatial and seasonal variations in avian assemblages in Taiwan. Ph.D. thesis. National Taiwan University. (In Chinese).

Shiu, H.-J. and Lee, P.-F. (2003) Seasonal variation in bird species richness along elevational gradients in Taiwan. Acta Zool. Taiwan. 14: 1-21.

Stockwell, D. R. B. and Peterson, A. T. (2002) Effects of sample size on accuracy of species distribution models. Ecol. Modell. 148: 1-13.

Stockwell, D. R. B., Beach, J. H., Stewart, A., Vorontsov, G., Vieglais, D. and Pereira, R. S. (2006) The use of the GARP genetic algorithm and internet grid computing in the Lifemapper world atlas of species biodiversity. Ecol. Modell. 195: 139-145.

Thuiller, W., Lafourcade, B., Engler, R. and Araújo, M. B. (2009) BIOMOD - a platform for ensemble forecasting of species distributions. Ecography 32: 369-373.

Václavík, T. and Meentemeyer, R. K. (2012) Equilibrium or not? Modelling potential distribution of invasive species in different stages of invasion. Diversity Distrib. 18: 73-83.

Walther, B. A., Schäffer, N., van Niekerk, A., Thuiller, W., Rahbek, C. and Chown, S. L. (2007) Modelling the winter distribution of a rare and endangered migrant, the Aquatic Warbler Acrocephalus paludicola. Ibis 149: 701-714.

Walther, B. A., van Niekerk, A., Thuiller, W., Baumann, S., Dean, W. R. J., de Bruijn, B., Gutteridge, K., Jones, P. J., Nikolaus, G.,
Pearson, D. J., Robinson, S. P., Salewski, V., Schäffer, N., Taylor, P. B., Tushabe, H., Williams, P. H. and Rahbek, C. (2010) A database of Western Palearctic birds migrating within Africa to guide conservation decisions. Cape Town, South Africa: University of Cape Town, Avian Demography Unit.

Walther, B. A., Wisz, M. S. and Rahbek, C. (2004) Known and predicted African winter distributions and habitat use of the endangered Basra reed warbler (Acrocephalus griseldis) and the near-threatened cinereous bunting (Emberiza cineracea). J. Ornithol. 145: 287-299.

Walther, B. A., Wu, T.-Y., Chen, Y.-H., Lin, R.-S. and Lee, P.-F. (2011) Using species distribution models to assess the rarity and conservation status of Taiwanese birds. Taiwan J. Biodivers. 13: 295-322.

Wang, C.-H., Wu, S.-H., Huang, K.-Y., Yang, H.-Y., Tsai, C.-H., Tsai, M.-C. and Hsiao, C.-L. (1991) The field guide of the birds of Taiwan. Taipei, Taiwan: Yashen Press. (In Chinese).

Wisz, M. S., Hijmans, R. J., Li, J., Peterson, A. T., Graham, C. H. and Guisan, A. (2008) Effects of sample size on the performance of species distribution models. Diversity Distrib. 14: 763-773.

Wisz, M. S., Walther, B. A. and Rahbek, C. (2007) Using potential distributions to explore determinants of Western Palaearctic migratory songbird species richness in subSaharan Africa. J. Biogeogr. 34: 828-841.

TSAI-YU WU, YI-HSIU CHEN, PEI-FEN LEE*

Institute of Ecology and Evolutionary Biology, National Taiwan University, Taipei, 106, Taiwan.

BRUNO A. WALTHER

Master Program in Global Health and Development, College of Public Health and Nutrition, Taipei Medical University, 250 Wu-Hsing St., Taipei 110, Taiwan.

RUEY-SHING LIN

Endemic Species Research Institute, 1 Ming-Shen East Road, Jiji, Nantou 552, Taiwan.

${ }^{*}$ Author for correspondence; e-mail: leepf@ntu.edu.tw

Received 4 January 2012; revision accepted 9 April 2013; Published online 21 June 2013 